\title{
PRÁTICAS DE GESTÃO DE CUSTOS ADOTADAS POR ORGANIZAÇÕES PAULISTAS DO SETOR DE ABRASIVOS E REFRATÁRIOS: UM ESTUDO COMPARATIVO
}

Valmor Reckziegel

vreckziegel@yahoo.com.br

Universidade Estadual do Oeste do Paraná

Debora Gomes Machado

deboramachado@furg.br

Universidade Federal do Rio Grande
Regiane de Souza Piva

regipva@yahoo.com.br

Universidade Estadual do Oeste do Paraná

Francielly Simões Lemke

fran_lemke@hotmail.com

Universidade Estadual do Oeste do Paraná

Resumo: Esta pesquisa teve como objetivo analisar a aderência/utilização das práticas de gestão de custos por organizações paulistas do setor de abrasivos e refratários, dentro do contexto de evolução dos estudos publicados por Souza, Lisboa e Rocha (2003) e Reckziegel, Souza e Diehl (2007). Inicialmente, o trabalho abordou a importância da contabilidade de custos como instrumento de controle e gestão, bem como a revisão de práticas para mensuração e gestão de custos, destacando o custeio e gestão baseada em atividades, o custo da qualidade, o custo-alvo, o custeio do ciclo de vida e a análise da cadeia de valor, defendidos por alguns autores como adequadas ao novo ambiente. $\mathrm{O}$ estudo foi realizado em cinco empresas pertencentes a um grupo empresarial situado na região da grande São Paulo, no intuito de investigar a realidade de setores diferentes dos abordados em estudos anteriores. Desenvolveu-se uma pesquisa levantamento, de cunho descritivo, por meio de questionário, com abordagem qualitativa. Os resultados evidenciam que as práticas de gestão de custos têm aceitação pelos gestores e profissionais da área, e, que dentro da necessidade informacional observa-se a aceitação por eles de novos instrumentos de gestão de custos. Especificamente com relação à aplicação do custeio e gestão baseada em atividades, os resultados demonstraram a não aceitação pelos gestores das empresas pesquisadas, confirmando resultados semelhantes aos estudos anteriores.

Palavras-chave: Gestão de Custos; Organizações Paulistas; Setor de Abrasivos e Refratários.

ABSTRACT: This research aimed to examine the adherenceluse of cost management practices by paulistas organizations of abrasives and refractory industry, within the context of developments in the studies published by Souza, Rocha and Lisbon (2003) and Reckziegel, Souza and Diehl (2007). Initially, the work has addressed the importance of cost accounting as a tool of control and management as well as the review of practices for measuring and managing costs, highlighting the activity based costing and activity based management, quality cost, target cost, the cost of living and the analysis of the value chain, defended by some authors as appropriate to the new environment cycle. The study was conducted in five companies belonging to a business group located in the Greater São Paulo region in order to investigate the reality of the different sectors addressed in previous studies. Developed a research survey, the descriptive paper, through a questionnaire, a qualitative approach. The results show that management practices have cost acceptance by managers and professionals, and that within the informational need observe the acceptance by them of new tools for managing costs. Specifically with regard to the application of activity based costing and activity based management, the results showed no acceptance by managers of the companies surveyed, confirming similar results to previous studies. 
Keywords: Cost Management; Paulistas Organizations; Abrasives and Refractories Sector.

Artigo recebido em: 27/02/2015; Aceito em: 20/09/2015

\section{INTRODUÇÃO}

É de consenso o reconhecimento, na pesquisa acadêmica, de que os empresários se defrontam com diversos problemas no gerenciamento de suas empresas, dentre estes se destaca as questões relativas à gestão e controle de custos, que passaram a ser ferramentas relevantes no contexto empresarial, pois o ambiente competitivo em que elas se encontram tem levado os administradores a buscarem uma série de novos recursos que possam auxiliá-los nas tarefas de controle, gestão e decisão, facilitando assim, o processo de gestão do negócio.

Neste contexto, segundo Souza, Lisboa e Rocha (2003) a contabilidade gerencial tem procurado, por meio do trabalho de vários pesquisadores, evoluir com o intuito de oferecer práticas específicas e tidas como adequadas e necessárias para gerar informações que os tomadores de decisão necessitam na condução competitiva das empresas.

Souza, Lisboa e Rocha (2003) salientam que devido a essa necessidade surgiram uma série de práticas e procedimentos inovadores, ou ocorreu o aperfeiçoamento de outras já existentes, objetivando suprir as lacunas identificadas pelos profissionais e teóricos da área de contabilidade, como por exemplo: o custeamento e gestão baseados em atividades, o custeamento por ciclo de vida dos produtos, o custeio alvo, o custo da qualidade, a análise de custos da cadeia de valores, os indicadores não financeiros e os custos de logística interna e de distribuição. Tais práticas são defendidas como apropriadas e consistentes à nova realidade dos sistemas produtivos das empresas, nos mercados competitivos e globalizados. Portanto, ajustadas às novas exigências informativas, visando à obtenção e/ou manutenção de vantagem competitiva.

Nessa perspectiva, a presente pesquisa contribui com o campo empresarial na gestão e controle, especificamente com as práticas de custos, por meio de verificação da adoção empírica em cinco empresas pertencentes a um grupo empresarial paulista, o qual desenvolve atividades referentes à produção de vidros, abrasivos, cerâmicas, plásticos, materiais de construção e de canalização.

Este artigo está estruturado em cinco seções, sendo a primeira composta pela contextualização do tema e apresentação do objetivo de pesquisa; a segunda abrange a revisão de literatura de suporte ao estudo; a terceira descreve os procedimentos metodológicos utilizados na realização da pesquisa; a quarta apresenta e analisa os resultados; a quinta apresenta as considerações finais da pesquisa. Por fim são elencadas as referências utilizadas em todo o aporte teórico da pesquisa.

\section{REVISÃO DE LITERATURA}

Nesta seção de revisão da literatura são abordados, sinteticamente, os métodos de custeio por absorção, baseado em atividades e o variável, e as seguintes práticas de gestão de custos: o custo alvo, o custeio do ciclo de vida, o custeio da qualidade e análise da cadeia de valor.

R. Cont. Ufba, Salvador-Ba, v. 9, n. 3, p. 81 - 103, set-dez 2015 


\subsection{Métodos de Custeio}

Diante da pesquisa da literatura, encontram-se proeminentes dois métodos de custeio: o absorção com evolução para o custeio baseado em atividade e o variável. Para Leone (1997) como ponto em comum é que estes se preocupam com a administração dos custos indiretos. Já como principal diferença é que cada um deles podem produzir diferentes informações que vão atender a necessidades distintas.

Conforme Leone (2000) o custeio por absorção consiste na apropriação dos custos diretos e indiretos de produção aos produtos elaborados. Os custos fixos são alocados aos produtos por meio de rateio, os custos variáveis são alocados diretamente aos produtos e as despesas são levadas diretamente a Demonstração de Resultados. Segundo Padoveze (2009) o custeio por absorção, por ser mais conservador deixa os empresários mais tranquilos, pois todos os custos foram apropriados e, devido a isso, os parâmetros para a formação de preço de vendas estariam com formação mais adequada.

O Padrão Contábil Internacional (PCI) requer que o estoque inclua todos os custos que o levaram a condição atual, portanto, em todos os países que adotam o PCI, é obrigatório o uso do custeio por absorção (ELDENBURG; WOLCOTT, 2007). O absorção é o único método de custeio aceito de mensuração para fins tributários. Por outro lado, é um método que possui limitações para fins gerenciais, pois utiliza critérios de rateio que podem chegar a resultados injustificados e assim ativar recursos indevidamente. Garrison e Noreen (2001) ratifica tal entendimento e destaca que esse método pode levar a problemas gerenciais por incluir decisões inadequadas de determinação de preço e decisões de deixar de fabricar produtos que na verdade são lucrativos.

Na pesquisa efetuada por Pitela et al. (2008), 66\% das empresas adotam esse método de custeio, pelo simples fato de ser um sistema que permite custear estoques e apurar resultados de acordo com as determinações legais e fiscais, não se preocupando com controles que ofereçam informações detalhadas.

Já o custeio baseado em atividades parte da premissa que as atividades consomem custos e que os produtos consomem essas atividades. Segundo Padoveze (2009) esse método procura aprimorar o custeamento dos produtos, através de mensurações mais acuradas dos custos fixos indiretos, com base nas atividades geradoras desses custos, para acumulação diferenciada ao custo dos diversos produtos da empresa.

Conforme Hansen e Mowen (2001) o ABC reflete a verdadeira relação entre os objetos de custo e a ocorrência dos custos reduzindo as distorções causadas por rateios arbitrários dos métodos tradicionais de custeio. Iudícibus et al. (2010) ressalta que os benefícios do ABC são maiores quando ele é utilizado para fins gerenciais, comtemplando, além de custos, outros gastos, para custear processos, mercados, classes de clientes etc.

Conforme Brimson (1996) as atividades descrevem o que a empresa faz e suas funções são converter recursos em bens ou serviços. $\mathrm{O}$ seu custeio permite às empresas conhecerem seus custos e desempenho (HANSEN; MOWEN, 2009).

O custeio variável atribui somente os custos e despesas variáveis aos produtos. Os custos fixos, que no custeio por absorção são rateados, no custo variável são levados diretamente para o resultado do período. Por isso, esse método não é ainda um critério plenamente consagrado, afirma Iudícibus et al. (2010).

Leone (2000) considera fundamentais as seguintes características do custeio variável: a) classifica os custos em fixos e variáveis, diretos e indiretos; b) debita ao segmento, cujo custo

R. Cont. Ufba, Salvador-Ba, v. 9, n. 3, p. 81 - 103, set-dez 2015 
está sendo apurado, apenas os custos que são diretos ao segmento e variáveis em relação ao parâmetro escolhido como base; c) os resultados apresentados sofrem influência direta do volume de vendas; d) é um critério administrativo, gerencial, interno; e) aparentemente sua filosofia básica contraria os preceitos geralmente aceitos de contabilidade, principalmente os fundamentos do regime de competência; f) apresenta a contribuição marginal, ou seja, a diferença entre as receitas e os custos diretos e variáveis do segmento estudado; g) o custeamento variável destinase a auxiliar, sobretudo, a gerência no processo de planejamento e de tomada de decisões e; $h$ ) como o custeamento variável trata dos custos diretos e variáveis de determinado segmento, o controle da absorção dos custos da capacidade ociosa não é bem explorado.

O emprego do custeio variável permite identificar os produtos que mais contribuem para a cobertura dos custos fixos. Estas informações auxiliam a traçar uma política comercial adequada, elegendo os produtos de maior rentabilidade e menor custo de produção. Salientam Eldenburg e Wolcott (2007) que essa forma de apresentar os custos melhora a capacidade dos gerentes de identificar os fluxos de caixa relevantes a um produto ou serviço para fins de processos decisórios internos. Na pesquisa de Pitela et al. (2008), foi constatado que apenas $15 \%$ das empresas pesquisadas utilizam esse método com intuito de prover análises de margens de contribuições.

Pesquisas tem demonstrado que o custeio variável possui informações de cunho gerencial que auxiliam no processo decisorial de curto prazo das organizações, como é o caso da pesquisa de Eyerkaufer, Costa, e Faria (2007). Os autores realizaram um estudo de caso com o objetivo de identificar e mensurar os custos de produção da ovinocultura de corte, por meio dos métodos de custeio por absorção e variável, visando demonstrar os valores dos estoques e os resultados econômicos de uma cabanha de ovinos de corte, em Itapiranga (SC). Os resultados da pesquisa demonstraram que, independentemente de o resultado econômico ser o mesmo no ano pelos dois métodos, a segregação mensal dos custos em variáveis e fixos, proposta pelo método do custeio variável, economicamente, é mais interessante para que os gestores da ovinocultura de corte tomem suas decisões de curto prazo.

O custeio variável foi apontado na pesquisa de Peleias et al. (2010), como o mais apropriado para as pequenas empresas, por permitir a distinção entre custos fixos e variáveis, o melhor entendimento da natureza e do comportamento desses custos em função dos volumes de produção e vendas, e a apuração da margem de contribuição. A investigação dos autores foi uma pesquisa-ação, com análise documental e observação presencial. O objetivo do estudo foi a criação de um conjunto de relatórios para a gestão de custos, a ser usado para otimizar os resultados de uma pequena empresa calçadista na cidade de São Paulo. A revisão da literatura, descrita pelos autores, revelou entraves no uso do custeio por absorção para fins gerenciais.

Em contraponto a pesquisa de Peleias et al. (2010), se para as pequenas empresas o custeio variável possui aderência relevante, nas grandes empresas o custeio por absorção demonstra ter uma utilização efetiva, conforme a pesquisa de Coronetti, Beuren, e Sousa (2012). Os autores buscaram nas maiores indústrias de diferentes ramos de atividades do Estado de Santa Catarina averiguar a adoção destes métodos de custeio. O estudo foi do tipo exploratório e levantamento ou survey e os dados foram coletados por meio de questionário enviado aos responsáveis pelo setor de custos de 35 empresas. Os resultados da pesquisa mostram que a maioria das empresas pesquisadas utiliza o método de custeio por absorção, tão somente ou em conjunto com outros métodos de custeio.

Os propósitos de usos dos métodos de custeio não são os únicos determinantes para sua efetiva utilização, Pinzan (2013) verificou, por meio de um estudo descritivo, correlacional e qualitativo, que, dentre os propósitos de uso de métodos de custeio que compõem o referencial

R. Cont. Ufba, Salvador-Ba, v. 9, n. 3, p. 81 - 103, set-dez 2015 
teórico de contabilidade gerencial e de contabilidade de custos os que se fazem presentes em cinco empresas que atuam no Brasil, do ramo automobilístico, ensino universitário, alimentos, cartões de benefícios e agronegócios. Os resultados da pesquisa do autor evidenciaram que, para análise de lucratividade e orçamento são utilizados métodos de custeio distintos e que o custeio absorção e variável são identificados com uma quantidade maior de propósitos de uso do que o custeio por atividade. Conforme o autor, em síntese os métodos de custeio não concorrem entre si, convivem harmonicamente de maneira complementar.

\subsection{Práticas de Gestão de Custos}

A gestão de custos, segundo Hansen e Mowen (2009) é o processo que identifica, coleta, mede, classifica e relata informações úteis aos gestores no processo de custeio, planejamento, controle e tomada de decisão. Dentro da extensão definida neste trabalho, as práticas de gestão de custos objeto da pesquisa são: Custo alvo, custeio do ciclo de vida, custo da qualidade e análise da cadeia de valor.

\subsubsection{Custo Alvo}

Custeio alvo é a diferença entre o preço de venda em relação a um mercado apropriado com o valor de lucro desejado determinando o custo máximo por unidade. Um método útil para se estabelecer metas de redução de custos durante o projeto do processo do produto. De acordo como Eldenburg e Wolcott (2007), o custeio alvo tem sido utilizado principalmente para produtos que já são fabricados por outras empresas. Entretanto, cada vez mais ele vem sendo usado para novos produtos e serviços.

O uso do custeio alvo em atividades econômicas cujos processos são simples acaba se tornando inadequado, pois são incapazes de diferenciar seus produtos com base na qualidade e funcionalidade. Exemplo disso foi demonstrado na pesquisa de Rosa, Camacho e Yu (2011), onde o custeio alvo foi testado numa empresa de comunicação visual com produção em produtos personalizados como convites de casamento. O custeio alvo é uma ferramenta gerencial com o objetivo de alcançar o custo alvo, pois trabalha com informações internas e externas. Para melhor entendimento pode-se utilizar a seguinte formula:

\section{Custo Máximo Admissível = Preço de Mercado (preço alvo) - Margem desejada}

Nesta fórmula o resultado encontrado é o custo máximo com o qual a empresa pode arcar sem prejudicar a margem desejada.

O modelo de custeio alvo está sintetizado na figura 1.

R. Cont. Ufba, Salvador-Ba, v. 9, n. 3, p. 81 - 103, set-dez 2015 


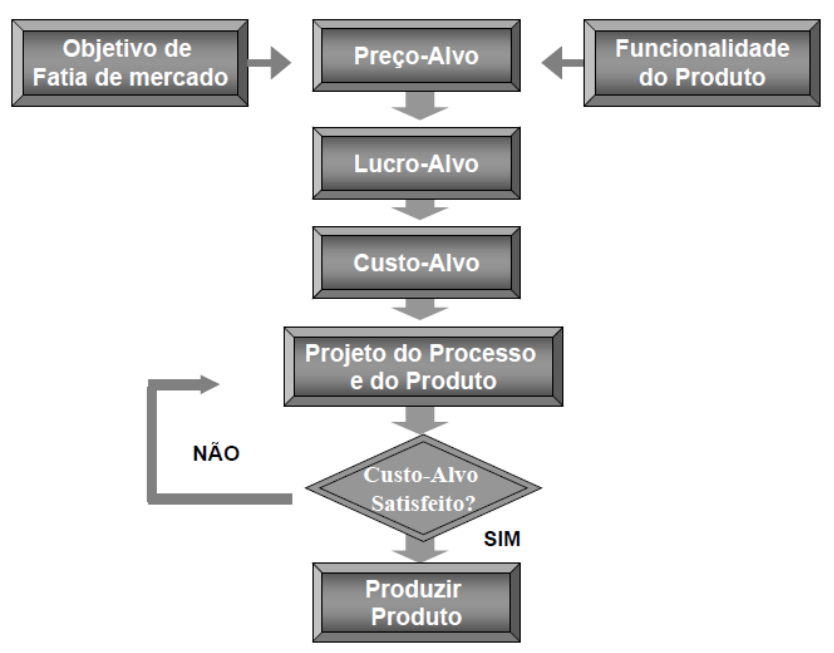

Figura 1 - Modelo de Custeio-Alvo

Fonte: Hansen e Mowen (2009, p. 444).

Como pode ser observado na figura 1, inicialmente o objetivo é atingir as necessidades dos clientes e o foco da empresa está nos produtos funcionais e preços competitivos. Em seguida é definido o custo a ser atingido e se o mesmo não for atingido, o processo retorna para a fase de projeto.

\subsubsection{Custeio do Ciclo de Vida}

O custeio do ciclo de vida é um método que considera a alteração de preços e custos ao longo de um clico de vida, desde quando o produto é introduzido no mercado até a sua retirada. Alguns produtos têm custos iniciais, como os de pesquisa; custos para mantê-los; custos para retirá-los do mercado. Às vezes os produtos não conseguem produzir receitas elevadas no início de sua vida, porém geram receitas durante seu ciclo de vida. Conforme Eldenburg e Wolcott (2007) sob o método do custeio alvo, esses produtos poderiam ser rejeitados, por outro lado, sob o custeio do ciclo de vida, os gerentes consideram a lucratividade do produto ao longo de diversos anos. O Quadro 1 descreve algumas características do custeio por ciclo de vida.

\begin{tabular}{|c|c|c|c|c|}
\hline & Introdução & Crescimento & Maturidade & Declínio \\
\hline Produto & $\begin{array}{l}\text { Projeto básico, poucos } \\
\text { modelos }\end{array}$ & $\begin{array}{l}\text { Alguma melhoria, linha } \\
\text { de produto ainda se } \\
\text { expandindo }\end{array}$ & $\begin{array}{l}\text { Proliferação das linhas de } \\
\text { produtos, diferenciação } \\
\text { extensiva }\end{array}$ & $\begin{array}{l}\text { Mudanças mínimas, } \\
\text { número reduzido de linhas } \\
\text { de produtos }\end{array}$ \\
\hline $\begin{array}{c}\text { Efeitos de } \\
\text { aprendizagem }\end{array}$ & $\begin{array}{l}\text { Altos custos, muita } \\
\text { aprendizagem, mas pouca } \\
\text { compensação financeira }\end{array}$ & $\begin{array}{l}\text { Ainda forte, } \\
\text { aprendizagem iniciando } \\
\text { a reduzir custos }\end{array}$ & $\begin{array}{l}\text { Produção estável, pouco } \\
\text { ou nenhum aprendizado }\end{array}$ & $\begin{array}{l}\text { Nenhuma aprendizagem, } \\
\text { mão-de-obra eficiente } \\
\text { quanto pode ser }\end{array}$ \\
\hline Preparações & $\begin{array}{l}\text { Poucas, mas novas e não- } \\
\text { familiares }\end{array}$ & $\begin{array}{l}\text { Mais, a medida } \\
\text { novos modelos } \\
\text { introduzidos }\end{array}$ & $\begin{array}{l}\text { Muitas à medida que } \\
\text { ocorre a diferenciação do } \\
\text { produto }\end{array}$ & $\begin{array}{l}\text { Pouquíssimas, à medida } \\
\text { que são produzidas apenas } \\
\text { linhas que vendem mais }\end{array}$ \\
\hline Compras & $\begin{array}{l}\text { Podem ser altas pois se } \\
\text { procuram materiais } \mathrm{e} \\
\text { fornecedores novos }\end{array}$ & $\begin{array}{l}\text { Mais baixas, foram } \\
\text { encontrados } \\
\text { fornecedores confiáveis, } \\
\text { poucas mudanças }\end{array}$ & $\begin{array}{lr}\text { Podem ser altas } \\
\text { dependendo } & \text { das } \\
\text { mudanças de linhas } & \end{array}$ & $\begin{array}{l}\text { Poucos fornecedores e } \\
\text { pedidos à medida que os } \\
\text { estoques existentes são } \\
\text { liquidados }\end{array}$ \\
\hline
\end{tabular}

R. Cont. Ufba, Salvador-Ba, v. 9, n. 3, p. 81 - 103, set-dez 2015 


\begin{tabular}{|c|lr|l|l|l|}
\hline $\begin{array}{c}\text { Despesas de } \\
\text { marketing }\end{array}$ & $\begin{array}{l}\text { Custos baixos de venda e } \\
\text { distribuição para umento } \\
\text { número pequeno de de } \\
\text { mercados-alvo }\end{array}$ & $\begin{array}{l}\text { Aumaganda de apoio, } \\
\text { propaganda } \\
\text { distribuição }\end{array}$ & $\begin{array}{l}\text { Propago de propaganda, } \\
\text { aumento nos descontos } \\
\text { comerciais, alto custo de } \\
\text { distribuiçação e promoção }\end{array}$ & \\
\hline
\end{tabular}

Quadro 1 - Impacto do Ciclo de Vida do Produto sobre a Gestão de Custos

Fonte: Hansen e Mowen (2009, p.683).

O conhecimento do ciclo de vida do produto é importante para a gestão de custos e segundo Hansen e Mowen (2009) é visível o impacto dos quatro estágios em marketing, e o crescimento e declínio em vendas. Menos óbvio é o impacto sobre os custos. Para introduzir um novo produto, existe a fase do aprendizado. O departamento de compras localiza fornecedores de matéria prima. $\mathrm{O}$ departamento de manufatura aprende a montar. A Figura 5 demonstra todo o processo e o impacto do ciclo de vida dos produtos.

\subsubsection{Custeio da Qualidade}

Consiste na medida dos custos associados ao sucesso e ao fracasso no processo de busca da qualidade, ou seja, qualquer despesa de fabricação que excedam aquelas despesas que teriam ocorrido caso o produto tivesse saído com perfeição desde a primeira vez. Custos de qualidade são os custos que existem porque a má qualidade existe (HANSEN; MOWEN, 2009).

Um produto de qualidade é aquele que satisfaz as expectativas do cliente e a qualidade vem se tornando uma dimensão competitiva importante para as organizações. As empresas estão implantando programas de melhoria da qualidade e segundo Hansen e Mowen (2009), surge a necessidade de monitorar e relatar o progresso desses programas. Os gestores precisam conhecer seus custos de qualidade e como estes estão mudando no decorrer do tempo.

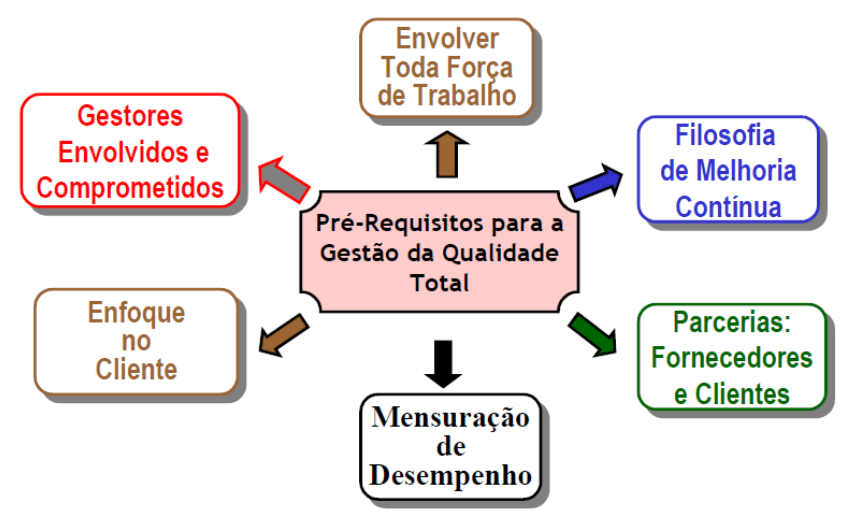

Figura 2 - Relações entre Gestão e Custeio da Qualidade Fonte: Elaborado a partir de Robles Jr. (1996).

Na figura 2 pode ser observada a necessidade do comprometimento de toda a organização para obter sucesso nos resultados do programa de qualidade. Conforme Hansen e Mowen (2009) os custos de qualidade podem ser classificados em dois grupos: custos de controle e custos da

R. Cont. Ufba, Salvador-Ba, v. 9, n. 3, p. 81 - 103, set-dez 2015 
falha no controle. O primeiro subdividido em prevenção e avaliação e o segundo em custos de falhas internas e custos de falhas externas.

Segundo os autores custos de prevenção são aqueles para evitar o aparecimento de defeitos, a má qualidade nos produtos ou serviços produzidos; os de avaliação são os incorridos para determinar se produtos e serviços estão em conformidade com os seus requisitos ou necessidades dos clientes; os de falhas internas são aqueles relacionados às falhas incorridas durante o processo de fabricação dos produtos antes do envio ou entrega às partes externas; e os de falhas externas são aqueles incorridos quando os produtos estão em desconformidade com os requisitos e necessidades dos clientes após a entrega.

Diante disso, entende-se que os custos de qualidade conseguem gerar benefícios em relação à redução de desperdícios e melhorias de produtos e processos quando mensurados e gerenciados corretamente. Para isso os administradores podem constituir um banco de dados para ajudar na identificação dos reflexos positivos e negativos integrado ao sistema de gestão da empresa.

\subsubsection{Análise da Cadeia de Valor}

As empresas lucrativas, em longo prazo, buscam maneiras de se tornar mais eficientes, aperfeiçoar suas relações com clientes e fornecedores e reduzir custos. Segundo Eldenburg e Wolcott (2007) cadeia de valor é uma sequência de processos econômicos na qual se vai agregando valor a um determinado produto ou serviço.

Com o estudo de cada passo do processo econômico é possível eliminar algumas atividades que não agregam valor à organização. Essa análise também se estende aos fornecedores e clientes, e inclui o compartilhamento do planejamento, do estoque, dos recursos humanos, dos sistemas de tecnologia de informação e mesmo das culturas empresariais. (ELDENBURG E WOLCOTT, 2007).

Para Hansen e Mowen (2009) a análise da cadeia de valores é a identificação e a exploração de ligações internas e externas com o objetivo de fortalecer a posição estratégica de uma empresa. Há certa necessidade de buscar reduções nos custos sem sacrificar o lucro da empresa pelo fato da forte concorrência no ambiente operacional em que a disputa por preços baixos e mercado é fator de sobrevivência. A Figura 3 apresenta um exemplo da cadeia de valor para o setor petrolífero

R. Cont. Ufba, Salvador-Ba, v. 9, n. 3, p. 81 - 103, set-dez 2015 


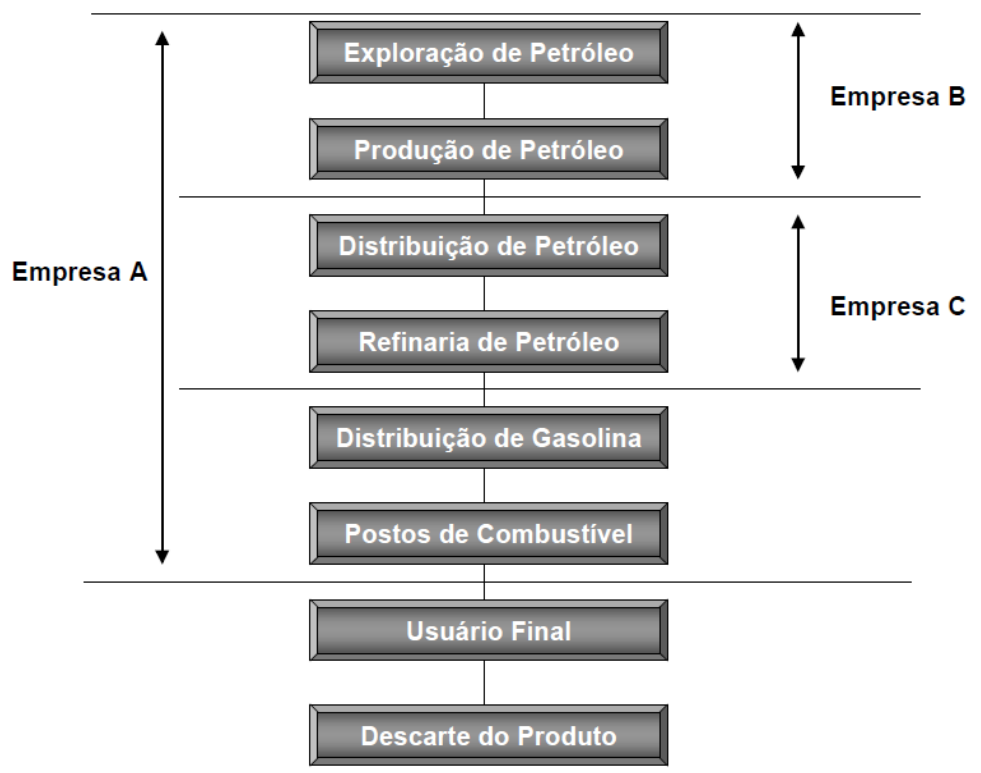

Figura 3 - Cadeia de Valor para o Setor Petrolífero Fonte: Hansen e Mowen (2009, p.426).

Observa-se na Figura 3 que algumas empresas participam de toda a cadeia e outras somente de uma parte. Para a empresa B e C competirem com a empresa A, isoladamente não é viável, o ideal seria competir entre elas de modo que chegue ao consumidor num preço final abaixo do praticado pela empresa A. Dessa forma conseguem atuar de forma competitiva.

\section{PROCEDIMENTOS METODOLÓGICOS}

Esse estudo objetiva analisar a aderência/utilização das práticas de gestão de custos por organizações paulistas do setor de abrasivos e refratários. Quanto à forma de abordagem a pesquisa se classificada como qualitativa, pois se busca percepções e entendimentos sobre a natureza geral de uma questão. Segundo Gil (2002), o estudo é qualitativo, quando não são utilizadas técnicas estatísticas na elucidação da problemática.

Com relação aos objetivos a pesquisa é classificada como descritiva, ou seja, procura descobrir, com a precisão possível, a frequência com que um fenômeno ocorre, sua relação e conexão com outros, sua natureza e características (CERVO; BERVIAN, 1996).

O instrumento de coleta de dados utilizado neste estudo foi um questionário, adaptado de Souza, Lisboa e Rocha (2003) e Reckziegel, Souza e Diehl (2007). O questionário foi estruturado com 15 questões de múltipla escolha a fim de atender aos objetivos de pesquisa. A escolha das empresas foi intencional por acessibilidade, e os respondentes foram os responsáveis pelas informações de custo nas empresas do setor de abrasivos e refratários. Foram selecionadas cinco empresas pertencentes ao setor justificado pelo acesso do pesquisador aos respondentes. A pesquisa foi realizada por meio de entrevista, com o uso de questionário pré-estruturado. A análise dos resultados foi descritiva.

\section{ANÁLISE E DISCUSSÃO DOS RESULTADOS}

R. Cont. Ufba, Salvador-Ba, v. 9, n. 3, p. 81 - 103, set-dez 2015 
A metodologia de custeio deve ser aderente aos princípios contábeis para atender as exigências legais, por isso o uso do custeio por absorção, notadamente pelos estudos anteriores realizados, vide Quadro 1, é o mais utilizado. Já para a tomada de decisão, a empresa pode optar por quaisquer práticas de gestão de custo que satisfaça as necessidades do administrador. Diante de pesquisas e estudos de casos de diversos autores foi possível elaborar o Quadro 2.

\begin{tabular}{|c|c|c|c|c|}
\hline Autores & Setores e seleção & $\begin{array}{l}\text { Práticas e } \\
\text { métodos } \\
\text { estudados }\end{array}$ & $\begin{array}{l}\text { Qde. em- } \\
\text { presas }\end{array}$ & Resultados \\
\hline $\begin{array}{l}\text { Souza, Lisboa } \\
\text { e Rocha } \\
(2003)\end{array}$ & $\begin{array}{l}\text { Subsidiárias Brasileiras } \\
\text { de empresas } \\
\text { multinacionais }\end{array}$ & $\begin{array}{c}\text { ABC/custo da } \\
\text { qualidade/custo } \\
\text { alvo/ciclo de } \\
\text { vida/analise da } \\
\text { cadeia de valor/etc. } \\
\end{array}$ & 39 & $\begin{array}{l}\text { No ambiente decisorial das empresas é } \\
\text { preponderantemente tradicional. }\end{array}$ \\
\hline $\begin{array}{l}\text { Reckziegel, } \\
\text { Souza e Diehl } \\
\quad(2007)\end{array}$ & $\begin{array}{l}\text { Empresas das regiões } \\
\text { noroeste e oeste do } \\
\text { estado do Paraná }\end{array}$ & $\begin{array}{l}\text { ABC/custo da } \\
\text { qualidade/custo } \\
\text { alvo/ciclo de } \\
\text { vida/analise da } \\
\text { cadeia de valor }\end{array}$ & 30 & $\begin{array}{l}\text { A preferência das empresas é pelos } \\
\text { métodos tradicionais. Não há aderência às } \\
\text { práticas de gestão de custos recentemente } \\
\text { desenvolvidas. }\end{array}$ \\
\hline $\begin{array}{l}\text { Santos, Bornia } \\
\text { e Leite (2010) }\end{array}$ & Empresa de alimentos & $\begin{array}{l}\mathrm{ABC} / \text { cadeia de } \\
\text { valor }\end{array}$ & 1 & $\begin{array}{c}\text { O resultado obtido foi viável para a } \\
\text { empresa diante das correções propostas } \\
\text { através da cadeia de valor e da aplicação } \\
\text { do método ABC }\end{array}$ \\
\hline $\begin{array}{l}\text { Souza, Silva e } \\
\text { Pilz (2010) }\end{array}$ & $\begin{array}{l}\text { Uma empresa } \\
\text { multinacional Brasileira }\end{array}$ & $\begin{array}{c}\text { ABC/Custeio do } \\
\text { ciclo de vida/ custeio } \\
\text { da qualidade/ custo } \\
\text { alvo/cadeia de } \\
\text { valor/etc. }\end{array}$ & 1 & $\begin{array}{l}\text { Observou o forte uso do custo padrão e à } \\
\text { necessidade da cadeia de valor. Identificou } \\
\text { falta de planos para a adoção do } \\
\text { ABC/custo meta }\end{array}$ \\
\hline $\begin{array}{c}\text { Pereira e } \\
\text { Espejo }(2010)\end{array}$ & $\begin{array}{l}\text { Hotéis de médio e } \\
\text { grande porte da cidade } \\
\text { de Salvador - BA }\end{array}$ & $\begin{array}{c}\text { Absorção/Variável/A } \\
\text { BC }\end{array}$ & 32 & $\begin{array}{l}\text { Os hotéis pesquisados fazem pouco uso } \\
\text { dessas práticas na definição das } \\
\text { prioridades estratégicas, talvez por falta de } \\
\text { um setor de contabilidade ou devido à } \\
\text { concorrência no setor. }\end{array}$ \\
\hline $\begin{array}{c}\text { Fernandes e } \\
\text { Slomski } \\
(2011)\end{array}$ & $\begin{array}{c}\text { Serviço Público nas } \\
\text { organizações brasileiras }\end{array}$ & Custeio da Qualidade & 16 & $\begin{array}{l}\text { Somente } 1 / 4 \text { de rejeição a prática - } \\
\text { apontaram pior comprometimento da alta } \\
\text { direção com processo de gestão de custos. }\end{array}$ \\
\hline $\begin{array}{l}\text { Silva e } \\
\text { Mendonça } \\
(2011)\end{array}$ & $\begin{array}{l}\text { Setor Varejista de } \\
\text { Vestuário }\end{array}$ & $\begin{array}{l}\text { Absorção/ Variável/ } \\
\text { Pleno }\end{array}$ & 174 & $\begin{array}{l}\text { Custeio por Absorção foi o mais citado } \\
\text { entre os respondentes (44\%) pela } \\
\text { simplicidade de aplicação, seguido do } \\
\text { Variável (10\%) e Pleno (6\%) - restante não } \\
\text { souberam responder }\end{array}$ \\
\hline $\begin{array}{l}\text { Pinheiro, } \\
\text { Rodrigues e } \\
\text { Barreto } \\
(2011)\end{array}$ & $\begin{array}{l}\text { Prestadoras de serviços } \\
\text { educacionais }\end{array}$ & $\mathrm{ABC}$ & 1 & $\begin{array}{l}\text { A proposta buscou atender as condições } \\
\text { atuais da organização. Acredita-se que se a } \\
\text { Instituição aderir a implantação de } \\
\text { reorganizações na estrutura, os resultados } \\
\text { poderão ser aperfeiçoados }\end{array}$ \\
\hline $\begin{array}{l}\text { Ferreira e } \\
\text { Schnorr } \\
(2011)\end{array}$ & $\begin{array}{l}\text { Custos Logísticos numa } \\
\text { empresa gaúcha do setor } \\
\text { alimentício }\end{array}$ & $\mathrm{ABC}$ & 1 & $\begin{array}{c}\text { Utiliza a Contabilidade de Ganhos com } \\
\text { base para a identificação das informações } \\
\text { de custos. Não há perspectivas de troca de } \\
\text { método, visto que o atual atende as } \\
\text { necessidades }\end{array}$ \\
\hline \begin{tabular}{c|} 
Pereira, \\
Vasconcelos e \\
Luz (2011)
\end{tabular} & $\begin{array}{c}\text { Micros e pequenas } \\
\text { empresas em Campina } \\
\text { Grande - PB }\end{array}$ & $\begin{array}{c}\text { Custo da } \\
\text { qualidade/cadeia de } \\
\text { valor } \\
\end{array}$ & 10 & $\begin{array}{l}\text { Nenhuma empresa pesquisada possui um } \\
\text { sistema de custo e nem cadeia de valor. }\end{array}$ \\
\hline
\end{tabular}

R. Cont. Ufba, Salvador-Ba, v. 9, n. 3, p. 81 - 103, set-dez 2015 


\begin{tabular}{|c|c|c|c|c|}
$\begin{array}{c}\text { Rosa, } \\
\text { Camacho e } \\
\text { Yu (2011) }\end{array}$ & $\begin{array}{c}\text { Empresa de } \\
\text { Comunicação Visual }\end{array}$ & Custeio Alvo & 1 & $\begin{array}{c}\text { Resultado obtido pode não ser vantajoso, } \\
\text { mas nada impede que a empresa utilize o } \\
\text { método. }\end{array}$ \\
\hline
\end{tabular}

Quadro 2 - Resumo dos estudos sobre aplicação de métodos e práticas de custeio

Fonte: Elaborado a partir da revisão de literatura.

Percebe-se, conforme a visualização do Quadro 2, pelos resultados de estudos anteriores, que as empresas não dão a devida atenção às práticas de gestão de custos e que ainda existem resistências na sua aplicação, as vezes por falta de conhecimento dos gestores e outras vezes pelo grau de complexidade ou dificuldade. Mesmo os que possuem uma cultura de gestão na empresa, nota-se que ainda há a necessidade de evolução mais acentuada nas práticas adotadas, comparativamente aos conceitos da literatura mais recente.

Diante de tais considerações, ficou evidente no decorrer da pesquisa a importância da utilização do sistema de custeio em busca de informações gerenciais e tomadas de decisões. Pinheiro, Rodrigues e Barreto (2011) entendem que o uso do sistema de custeamento aliado ao planejamento estratégico pode produzir redução nos custos, controle interno e vantagem competitiva sustentável.

\subsection{Perfil das Empresas Pesquisadas}

As cinco empresas pesquisadas possuem as seguintes características estão sediadas na região da grande São Paulo, pertencerem a um grupo empresarial, são do ramo de abrasivos e refratários e enquadram-se como de grande porte, pois faturam acima de 60 milhões de reais por ano.

Quanto aos cargos ocupados pelos respondentes, foi possível verificar que os profissionais estão direta ou indiretamente relacionados à área de custos, infelizmente $60 \%$ dos entrevistados não informaram a posição ocupada na empresa. Assim sendo, o perfil dos entrevistados se apresenta na Tabela 1.

Tabela 1 - Cargos Ocupados pelos Entrevistados

\begin{tabular}{|c|c|c|}
\hline Cargos & Quantidade & $\%$ \\
\hline Gerente Financeiro & 1 & 20 \\
\hline Coordenador de Controladoria Industrial & 1 & 20 \\
\hline Não informou & 3 & 60 \\
\hline Total & 5 & 100 \\
\hline
\end{tabular}

Fonte: Dados da pesquisa.

\subsection{Práticas de Gestão de Custos}

Quanto ao uso das práticas de gestão de custos, no âmbito da amplitude delimitada neste estudo, as práticas de gestão de custos objeto da pesquisa são as seguintes: a) custeio e gestão baseada em atividades ( $\mathrm{ABC}$ e $\mathrm{ABM}$ ); b) custo da qualidade; c) custo-alvo; d) custeio do ciclo de vida dos produtos; e, e) análise da cadeia de valor.

Em virtude do não-fornecimento de determinados dados específicos por algumas empresas, por questões de confidencialidade alegadas pelas mesmas, destacando que algumas respostas obtidas foram objetivas e de baixa argumentação. Tal fato, entretanto, não ocorreu em número representativo a fim de comprometer os resultados da pesquisa.

R. Cont. Ufba, Salvador-Ba, v. 9, n. 3, p. 81 - 103, set-dez 2015 
Segundo Padoveze (2009, p. 331), método de custeamento "É o processo de identificar o custo unitário de um produto". Pela adoção do sistema de custeio, definem-se quais os custos que fazem parte dos produtos e quais devem ser alocados aos mesmos para se chegar ao custo unitário dos produtos fabricados. Portanto, a partir das informações de custos os gestores poderão tomar decisões necessárias à organização de acordo com as características particulares de cada empresa, proporcionando assim uma gestão e controle dos custos eficaz.

A fim de identificar qual o método de custeio as empresas dão preferência para calcular os custos dos produtos fabricados, formulou-se a seguinte pergunta: Questão 1 - Qual método de custeio utilizado na empresa, para fins gerenciais, na mensuração do custo dos produtos?

As respostas obtidas estão apresentadas na Tabela 2.

Tabela 2 - Método de Custeio Utilizado

\begin{tabular}{|c|c|c|}
\hline Método de custeio utilizado & $\mathrm{N}^{\circ}$ Empresas & $\%$ no grupo \\
\hline Conjugação de Absorção e Custo Padrão & 2 & 40 \\
\hline Conjugação de Variável e Custo Médio & 1 & 20 \\
\hline Custo Médio & 1 & 20 \\
\hline Não informou & 1 & 20 \\
\hline Total & 5 & 100 \\
\hline
\end{tabular}

Fonte: Dados da pesquisa.

Verifica-se, conforme a visualização da Tabela 2, que as empresas dão preferência na adoção do método conjugado do custeio absorção com o custo padrão (40\%), logo depois a conjugação de variável com o custo médio (20\%) e a utilização somente do custo médio (20\%). Comparando com o estudo de Souza, Lisboa e Rocha (2003) e Reckziegel, Souza e Diehl (2007) percebe-se uma expressiva preferência pela adoção do método de custeio por absorção pelas empresas, seguido pelo método de custeio variável e por último a conjugação destes dois métodos (absorção e variável).

Como forma de comprovar as respostas apresentadas à Questão 1, e possibilitar a identificação de possíveis contradições ao métodos adotados, sendo que a grande diferença de um método para outro está no tratamento que é dado a apropriação dos custos indiretos aos produtos, foram formuladas as questões 2 e 3. Questão 2 - Que custos são apropriados aos produtos?

As respostas estão apresentadas na Tabela 3, destacando-se que tanto na questão 2, como na 4, o elemento outros custos apresentados nas Tabelas 3 e 5, referem-se a custos de produção e não incluem despesas.

Tabela 3 - Custos Apropriados aos Produtos

\begin{tabular}{|c|c|c|c|}
\hline Elementos & $\mathrm{N}^{\mathrm{o}}$ Empresas & Amostra & $\%$ \\
\hline Matérias Primas & 5 & 5 & 100 \\
\hline Mão de Obra (MOD) & 4 & 5 & 80 \\
\hline Mão de Obra Indireta & 4 & 5 & 80 \\
\hline Depreciação & 4 & 5 & 80 \\
\hline Manutenção (Fábrica) & 4 & 5 & 80 \\
\hline Aguá / Luz / Telefone (Fábrica) & 4 & 5 & 80 \\
\hline Outros Materiais Indiretos & 4 & 5 & 80 \\
\hline Outros Custos & 2 & 5 & 40 \\
\hline
\end{tabular}

R. Cont. Ufba, Salvador-Ba, v. 9, n. 3, p. 81 - 103, set-dez 2015 
Fonte: Dados da pesquisa.

De acordo com a Tabela 3, em todas as empresas se apropria ao produto o custo da matéria prima (100\%). Em quatro empresas (80\%) além da matéria prima, os demais custos são apropriados para fins contábeis e somente duas empresas (40\%) apropriam outros custos aos produtos.

Questão 3 - Quanto aos custos que não são possíveis de serem identificados diretamente com o produto, e que necessitam de algum critério de rateio para sua apropriação, quais elementos são considerados como base para essa alocação? Com relação às bases de rateio dos custos adotadas nas empresas, o resultado da pesquisa está apresentado na Tabela 4.

Tabela 4 - Base de Rateio dos Custos aos Produtos

\begin{tabular}{|c|c|c|c|}
\hline Elementos & $\mathrm{N}^{\mathrm{o}}$ Empresas & Amostra & $\%$ \\
\hline Volume de Produção & 4 & 5 & 80 \\
\hline Quantidade de Matéria Prima & 2 & 5 & 40 \\
\hline Horas de Mão de Obra Direta & 3 & 5 & 60 \\
\hline Atividades Geradoras de Custo & 1 & 5 & 20 \\
\hline Outras Bases & 2 & 5 & 40 \\
\hline
\end{tabular}

Fonte: Dados da pesquisa.

Verifica-se a predominância do uso de bases de rateio relacionadas a volume de produção. Pelos dados da Tabela 4, destacam-se: volume de produção (80\%), horas de mão de obra direta (60\%). Diante dos dois questionamentos, percebe-se que as respostas demonstram consistência em relação aos métodos de custeio indicados nas respostas da Questão 1.

Questão 4 - Em decisões entre comprar ou fabricar, introdução ou corte de produtos, lançamento de novos produtos, e o impacto dessas decisões nos resultados da empresa, quais custos são considerados para tomar tais decisões? As respostas obtidas estão apresentadas na Tabela 5.

Tabela 5 - Custos Considerados para a Tomada de Decisões

\begin{tabular}{|c|c|c|c|}
\hline Elementos & $\mathrm{N}^{\mathrm{o}}$ Empresas & Amostra & $\%$ \\
\hline Matérias Primas & 5 & 5 & 100 \\
\hline Mão de Obra (MOD) & 4 & 5 & 80 \\
\hline Mão de Obra Indireta & 2 & 5 & 40 \\
\hline Depreciação & 4 & 5 & 80 \\
\hline Água / Luz / Telefone (Fábrica) & 4 & 5 & 80 \\
\hline Outros Materiais Diretos & 4 & 5 & 80 \\
\hline Outros Custos & 2 & 5 & 40 \\
\hline
\end{tabular}

Fonte: Dados da pesquisa.

Como pode ser observado na Tabela 5, em todas as empresas (100\%) o custo da matéria prima é considerado para a tomada de decisões. Apenas duas empresas (40\%) apontaram considerar a mão de obra indireta e outros custos na tomada de decisões e com relação aos demais custos, em quatro empresas $(80 \%)$ os mesmos são considerados na tomada de decisões, além do custo da matéria prima.

R. Cont. Ufba, Salvador-Ba, v. 9, n. 3, p. 81 - 103, set-dez 2015 
Após apresentar os resultados da pesquisa quanto à utilização do método de custeio adotado pelas empresas a próxima sessão se destina a analisar os resultados sobre o uso do Custeio e Gestão Baseado em Atividades (ABC e ABM). Eldenburg e Wolcott (2007) relatam que o $\mathrm{ABC}$ é um sistema utilizado para atribuir custos às atividades específicas realizadas num processo de fabricação de produtos ou de prestação de serviços. Por meio do ABC é possível identificar de forma mais acurada os custos aos produtos do que por métodos tradicionais de custeio. Com as informações fornecidas pelo ABC é possível utilizá-las a fim de aperfeiçoar as operações e minimizar as atividades que não agregam valor a organização, esse processo é chamado de gestão baseada em atividades (ABM).

Em face de todas essas argumentações, pesquisou-se a utilização, nas empresas, do custeio e gestão baseados em atividades, e as opiniões dos entrevistados quando a sua implantação. Questão 5 - Caso utilize o custeio e a gestão baseado em atividades (ABC/ABM), destaque as vantagens da sua utilização?

Dentre os entrevistados apenas uma empresa (20\%) utiliza o sistema de custeio e a gestão baseada em atividades (ABC e ABM), no qual, destacou que essas ferramentas possibilitam aos gestores maior qualidade de informação para tomada de decisões. Comparando com o estudo de Souza, Lisboa e Rocha (2003) e Reckziegel, Souza e Diehl (2007) percebe-se respectivamente, que apenas $2 \%$ e $6 \%$ das empresas adotaram o sistema ABC e ABM para os custos de produção, em contrapartida, $79,6 \%$ e $17 \%$ não tem planos futuros para adotar e $8,2 \%$ e $33 \%$ avaliou e descartou a possibilidade de adotar essa ferramenta. Visando identificar de forma mais objetiva o por quê da não adoção do $\mathrm{ABC}$ e $\mathrm{ABM}$, formulou-se a seguinte questão: Questão 6 - Caso não utilize o custeio e gestão baseado em atividades (ABC/ABM), identifique o por quê da não utilização?

Os principais comentários contrários a utilização do $\mathrm{ABC}$ estão ligados principalmente a complexidade de implantação e manutenção, no qual exige mudanças profundas no sistema, e que, no momento a atual sistema atende as necessidades da empresa. Comparando com o estudo de Souza, Lisboa e Rocha (2003) os argumentos contrários a utilização do ABC mais citados foram: (1) complexidade na implantação e manutenção do sistema, (2) custo envolvido para sua adoção e (3) dificuldade em justificar objetivamente os benefícios. Para Reckziegel, Souza e Diehl (2007) os comentários mais citados foram: (1) baixa relação custo x benefício na adoção do sistema, (2) o sistema atual é determinado na matriz e, portanto, não há opção de mudança e (3) o atual sistema atende as necessidades da organização.

Após apresentar os resultados da pesquisa quanto à utilização do $\mathrm{ABC}$ e $\mathrm{ABM}$, a próxima questão se destina a analisar os resultados sobre o uso do custo-alvo. De acordo com Martins (2010), o custeio-alvo é um processo de planejamento de lucros, preços e custos que parte do preço de venda para chegar ao custo, no entanto, muitas vezes o preço ideal não é capaz de produzir o resultado mínimo esperado ou de cobrir os gastos fixos, surge então à necessidade de saber o custo para então determinar o preço de venda. Com a crescente competitividade entre as empresas em um mercado em constante modificação, com clientes cada vez mais exigentes e ávidos por produtos que se ajustem mais as suas necessidades, o preço passa a ser formado praticamente em função da oferta e da procura. Reconhecendo a importância da adoção da prática do custo-alvo, e com o objetivo de obter a opinião dos entrevistados sobre sua utilização nas empresas, foi formulada a seguinte questão: Questão 7 - Como é calculado o preço de venda dos produtos na empresa? Considera os custos? Quais custos? As respostas obtidas dos entrevistados estão apresentadas na Tabela 6.

R. Cont. Ufba, Salvador-Ba, v. 9, n. 3, p. 81 - 103, set-dez 2015 
Tabela 6 - Elementos Considerados para Calcular o Preço de Venda

\begin{tabular}{|c|c|c|c|}
\hline Elementos & $\mathrm{N}^{\circ}$ Empresas & Amostra & $\%$ \\
\hline Matérias Primas & 4 & 5 & 80 \\
\hline Mão de Obra (MOD) & 3 & 5 & 60 \\
\hline Mão de Obra Indireta & 3 & 5 & 60 \\
\hline Depreciação & 3 & 5 & 60 \\
\hline Manutenção (Fábrica) & 3 & 5 & 60 \\
\hline Água / Luz / Telefone (Fábrica) & 3 & 5 & 60 \\
\hline Outros Custos & 3 & 5 & 60 \\
\hline Despesas & 2 & 5 & 40 \\
\hline Impostos & 4 & 5 & 80 \\
\hline Margem de Lucro Desejada & 5 & 5 & 100 \\
\hline Preço Praticado pela Concorrência & 3 & 5 & 60 \\
\hline
\end{tabular}

Fonte: Dados da pesquisa.

De acordo com o apresentado na Tabela 6, nas empresas pesquisadas em apenas duas (40\%) não consideram o preço praticado pela concorrência na formação do preço de venda de seus produtos. Os demais entrevistados reconheceram que é o mercado quem atualmente determina os preços. A maioria das empresas (60\%) utilizam dos elementos (matéria prima, mão de obra direta e indireta, manutenção da fábrica etc.) demonstrados na tabela para calcular o preço que efetivamente será praticado.

Com o intuito de complementar as informações relacionadas às estratégias adotadas pelas empresas para competir com níveis de preços semelhantes aos praticados pela concorrência, foi apresentada seguinte questão: Questão 8 - Que ações são tomadas caso o preço de venda dos produtos da empresa esteja acima dos praticados pela concorrência? As respostas obtidas dos entrevistados estão evidenciadas na Tabela 7.

Tabela 7 - Ações Para Adequação aos Preços da Concorrência

\begin{tabular}{|c|c|c|c|}
\hline Ações tomadas nas empresas & $\mathrm{N}^{\mathrm{o}}$ de empresas & Amostra & $\%$ \\
\hline Reduções de custo: substituição de componentes dos produtos & 2 & 5 & 40 \\
\hline Reduções de custo: outras estratégias & 4 & 5 & 80 \\
\hline Reduções na margem de lucro & 4 & 5 & 80 \\
\hline Não há o que fazer com os custos & 1 & 5 & 20 \\
\hline
\end{tabular}

Fonte: Dados da pesquisa.

Como exposto na Tabela 7, as empresas não utilizam somente de uma ação para adequar seus preços ao da concorrência, buscam adotar de forma conjunta certas ações a fim de reduzir seus custos. Diante das informações contidas na tabela, percebe-se que quatro empresas $(80 \%)$ acabam por sacrificar a margem de lucro para competir com os mesmos níveis de preços praticados pela concorrência e também utilizam de outras estratégias de custos quando o preço estabelecido for superior ao praticado no mercado. E apenas uma (20\%) afirmou que não há o que fazer com os custos. O estudo de Reckziegel, Souza e Diehl (2007), apontam que da amostra total, cada empresa empregava apenas uma ação para adequar aos preços da concorrência, sendo assim, em 19 empresas (63\%) efetuam a substituição de componentes dos produtos e outras

R. Cont. Ufba, Salvador-Ba, v. 9, n. 3, p. 81 - 103, set-dez 2015 
práticas de redução de custos e apenas $23 \%$ das empresas sacrificam a margem de lucro para manter-se no mercado.

Após ser apresentado e analisado o resultado da pesquisa quanto à utilização do custoalvo, a seguir são evidenciadas as respostas obtidas dos entrevistados quanto à mensuração e uso de informações relacionadas ao custo da qualidade.

Segundo Hansen e Mowen (2009), durante as últimas décadas, forças competitivas têm forçado as empresas a prestarem cada vez mais atenção à qualidade. Os clientes cada vez mais exigem produtos e serviços de alta qualidade. A melhoria da qualidade pode significar a sobrevivência de muitas empresas, pois pode aumentar a participação no mercado e as vendas e simultaneamente reduzir custos. Neste contexto, procurou-se identificar se nas empresas são mensurados os custos da qualidade. Primeiramente foi questionado se há certificação do programa de qualidade, através da seguinte questão: Questão 9 - A empresa tem certificação de programa de controle de qualidade? As respostas obtidas dos entrevistados quanto a programas de qualidade certificadas pelas normas ISO, estão descritas na Tabela 8.

Tabela 8 - Programa de Qualidade Implementado

\begin{tabular}{lccc}
\hline & Tipo de certificação & Empresas & $\%$ \\
\hline Certificação ISO & 3 & 60 \\
Está em fase de implementação da ISO & & 1 & 20 \\
Não respondeu & Total & 1 & 20 \\
\hline & & 5 & 100 \\
\hline
\end{tabular}

Fonte: Dados da pesquisa.

Como pode ser observado na Tabela 8, três empresas (60\%) possuem programa de qualidade certificado e uma (20\%) está em fase de implementação, infelizmente, uma empresa não respondeu essa questão. A seguir, com o objetivo de identificar se nas empresas era adotado o custo da qualidade, foi elaborada a seguinte questão: Questão 10 - Na empresa há registro dos custos da qualidade? Se sim, quais são eles? Para reduzir os riscos de viés nas respostas, a questão continha os elementos principais que constituem os custos da qualidade. As respostas obtidas estão apresentadas na Tabela 9.

Tabela 9 - Custos da Qualidade Controlados

Elementos

$\mathrm{N}^{\mathrm{o}}$ Empresas

Empresas

Certificadas

Inspeção de produtos

Treinamentos (pessoal da produção)

Inspeção (desenvolvimento e compra de equipamentos)

Avaliação (teste de inspeção)

Auditorias (operações, produtos, estoques)

Manutenção (equipamentos de testes)

Aprovação de fornecedores (requisitos de qualidade)

Material fornecido com defeito

Desperdício (matérias-primas, mão-de-obra, retrabalho)

Garantias (reparos, reclamações, devoluções)

$\begin{array}{cc}4 & 100 \\ 4 & 100 \\ 4 & 25 \\ 4 & 50 \\ 4 & 100 \\ 4 & 50 \\ 4 & 50 \\ 4 & 50 \\ 4 & 50 \\ 4 & 100\end{array}$

R. Cont. Ufba, Salvador-Ba, v. 9, n. 3, p. 81 - 103, set-dez 2015 
Responsabilidade civil (processos judiciais)

Fonte: Dados da pesquisa.

Como pode ser observado na Tabela 9, em apenas uma empresa $(25 \%)$ das que possuem certificação de qualidade, há controle sobre a insatisfação dos clientes. Outro ponto observado é que todas as empresas (100\%) fazem a inspeção de produtos, treinamentos, auditorias e dão garantia do seu produto. Com o propósito de identificar o motivo da não adoção dos princípios do custo da qualidade, foi formulada a seguinte questão: Questão 11 - Caso na empresa não existe um controle dos custos da qualidade, destaque as principais justificativas.

Como todas as empresas que possuem programa de qualidade certificado fazem um controle dos custos da qualidade, não houve nenhum apontamento nesta questão. E a única empresa que não respondeu a questão 9 (se possui certificado de qualidade), também não informou suas justificativas por não ter esse controle dos custos da qualidade nesta questão.

Finalizada a análise do custo da qualidade, e em continuidade a apresentação dos resultados do presente estudo, a seguir são tratados aqueles obtidos quanto à utilização prática dos princípios do custeio do ciclo de vida dos produtos. De acordo com Eldenburg e Wolcott (2007, p. 528), o custeio do ciclo de vida é "um método de tomada de decisão que considera as alterações no preço e nos custos ao longo de todo um ciclo de vida de um produto ou serviço, durante vários anos, desde o instante em que é introduzido no mercado." Com o objetivo de obter a opinião dos entrevistados sobre o assunto, foi formulada a seguinte questão: Questão 12 - $O$ meio acadêmico defende que há alguns custos que são gerados durante a fase de projeto do produto, outros durante a fase de produção dos produtos, alguns para manter o produto no mercado e ainda alguns custos para retirar os produtos do mercado, e que devem ser controlados pela empresa. Quais custos são controlados na empresa? As respostas obtidas dos entrevistados estão apresentadas na Tabela 10.

Tabela 10 - Custos Controlados Pelas Empresas

\begin{tabular}{lccc}
\multicolumn{1}{c}{ Elementos } & Empresas & Amostra & $\%$ \\
\hline Custos de projeto dos produtos (fase pioneira) & 4 & 50 \\
Custos de fabricação (fase da produção) & 4 & 5 & 80 \\
Custos de manutenção do produto no mercado (fase de estabilização) & 3 & 5 & 60 \\
Custos de substituição do produto (fase declínio) & 1 & 5 & 20 \\
\hline
\end{tabular}

Fonte: Dados da pesquisa.

Segundo os dados da tabela 10, nas empresas pertencentes à amostra pesquisada, quatro empresas (80\%) mantêm o tradicional controle dos custos internos de produção, no entanto se preocupam também com os custos que podem ser gerados após a venda dos produtos, em três casos $(60 \%)$, os entrevistados comentaram que consideram os custos para manter o produto no mercado. Comparando com estudo de Reckziegel, Souza e Diehl (2007) percebe-se que as empresas davam preferência ao controle dos custos na fase pioneira (57\% das empresas) e na fase de produção (100\%), deixando a desejar na fase de estabilização onde apenas $7 \%$ das empresas faziam esse controle e não controlavam na fase de declínio (0\%).

Questão 13 - Caso na empresa não se efetue um planejamento e controle dos custos nas fases de planejamento, manutenção e retirada do produto do mercado, indique as possíveis justificativas.

R. Cont. Ufba, Salvador-Ba, v. 9, n. 3, p. 81 - 103, set-dez 2015 
As principais justificativas apresentadas pelos entrevistados para a não adoção da prática do custeio do ciclo de vida foram: (1) produtos tem longos ciclos de vida e (2) os produtos são executados em grande escala. Após apresentar os resultados quanto à adoção do custeio do ciclo de vida dos produtos, a seguir são demonstrados os referentes a utilização dos princípios da análise da cadeia de valor.

Para entender o que abrange uma cadeia de valor, Eldenburg e Wolcott (2007), explanam que é uma sequência de processos econômicos na qual se vai agregando valor a um determinado produto ou serviço. Deste modo a análise da cadeia de valores leva a um aperfeiçoamento das relações entre a organização e outras partes constituintes dessa mesma cadeia, criando uma organização de conexões amplas e capaz de responder de modo flexível aos ambientes dinâmicos e competitivos. Baseando-se neste entendimento, o presente estudo procurou identificar na amostra pesquisada se estão sendo exploradas tais oportunidades com a seguinte questão: Questão 14 - Na empresa se explora oportunidades de redução de custo utilizando ligações com fornecedores, clientes, ligações de processo, unidades da empresa e concorrentes? As respostas obtidas dos entrevistados estão apresentadas na Tabela 11.

Tabela 11 - Ligações Efetuadas Pelas Empresas Para Redução de Custo

\begin{tabular}{|c|c|c|c|}
\hline Elementos & Empresas & Amostra & $\%$ \\
\hline Ligações com fornecedores & 4 & 5 & 80 \\
\hline Ligações com clientes & 3 & 5 & 60 \\
\hline Ligações de processo interno & 5 & 5 & 100 \\
\hline Ligações com unidades empresariais & 2 & 5 & 40 \\
\hline
\end{tabular}

Fonte: Dados da pesquisa.

O resultado apresentado demonstra a preocupação das entidades para redução do custo, utilizando as ligações internas para melhoria conjunta dos processos da empresa, no qual todas as empresas (100\%) exploram essa oportunidade, $80 \%$ utilizam de ligações com fornecedores e $60 \%$ das empresas utilizam ligações com os clientes e apenas duas delas (40\%) usam as ligações com unidades empresariais para redução de custo. Comparando com estudo de Reckziegel, Souza e Diehl (2007) apenas 63\% das organizações adotam ligações com fornecedores, cliente e concorrentes, contra $37 \%$ da amostra que não exploram as oportunidades.

Questão 15 - Caso na empresa não se explorem oportunidades de redução de custo com fornecedores, clientes, unidades empresariais elou concorrentes, destaque a justificativa da não utilização. Devido à $100 \%$ das empresas adotarem a análise da cadeia de valor, item respondido na questão anterior, não há necessidade de responder tal questão.

\section{CONSIDERAÇÕES FINAIS}

Partindo da premissa de que uma das formas de evolução do conhecimento científico sobre determinada matéria é a investigação da utilidade e da aplicabilidade de seus desenvolvimentos teóricos, este estudo atingiu os seus propósitos, pois, por meio dele, foi possível, no âmbito das empresas pesquisadas, verificar o grau de aderência das práticas de gestão de custos comparativamente ao exposto na literatura e aos estudos realizados por Souza, Lisboa e Rocha (2003) e Reckziegel, Souza e Diehl (2007) o que possibilitou inferir sobre uma evolução quanto à utilização destas práticas. Diante deste contexto, para alcançar o objetivo proposto por este estudo, que era de verificar o efetivo nível de utilização de práticas de gestão de

R. Cont. Ufba, Salvador-Ba, v. 9, n. 3, p. 81 - 103, set-dez 2015 
custos considerando a evolução dos estudos publicados por Souza, Lisboa e Rocha (2003) e Reckziegel, Souza e Diehl (2007) foi formulado o quadro $3 \mathrm{com}$ as devidas pesquisas e resultados alcançados.

Quadro 3 - Comparação nos achados em relação aos estudos anteriores

\begin{tabular}{|c|c|c|c|c|}
\hline Práticas & $\begin{array}{c}\text { Souza, Lisboa e } \\
\text { Rocha (2003) }\end{array}$ & $\begin{array}{c}\text { Reckziegel, Souza e } \\
\text { Diehl (2007) }\end{array}$ & Estudo atual & Resultados \\
\hline $\begin{array}{l}\text { Custeio e } \\
\text { Gestão } \\
\text { Baseados em } \\
\text { Atividades } \\
\text { (ABC e ABM) }\end{array}$ & $\begin{array}{l}\text { Não utilizam e não } \\
\text { tem planos futuros } \\
\text { para adoção da } \\
\text { ferramenta. }\end{array}$ & $\begin{array}{l}\text { Não utilizam, porém, } \\
\text { algumas empresas têm } \\
\text { planos futuros para adoção } \\
\text { da ferramenta. }\end{array}$ & $\begin{array}{l}\text { Não utilizam e não } \\
\text { tem planos futuros } \\
\text { para adoção da } \\
\text { ferramenta. }\end{array}$ & $\begin{array}{l}\text { Aderente aos estudos } \\
\text { anteriores, pois teve achado } \\
\text { semelhante. }\end{array}$ \\
\hline Custo-Alvo & Não pesquisou. & $\begin{array}{l}\text { Utilizam a ferramenta, no } \\
\text { entanto não exploravam } \\
\text { todas as ações para redução } \\
\text { dos custos. }\end{array}$ & $\begin{array}{l}\text { Utilizam a ferramenta } \\
\text { explorando todas as } \\
\text { ações para atingir o } \\
\text { preço e o custo ideal. }\end{array}$ & $\begin{array}{l}\text { Aderente ao estudo anterior, } \\
\text { pois teve achado semelhante, } \\
\text { e, houve evolução quanto à } \\
\text { utilização desta prática. }\end{array}$ \\
\hline $\begin{array}{l}\text { Custo da } \\
\text { Qualidade }\end{array}$ & Não pesquisou. & $\begin{array}{l}\text { Apesar de não ser tão usada, } \\
\text { as empresas estavam em fase } \\
\text { de implementação da ISO e } \\
\text { outras planejavam } \\
\text { implementar a ISO. }\end{array}$ & $\begin{array}{l}\text { Utilização } \\
\text { significativa desta } \\
\text { ferramenta pelas } \\
\text { empresas } \\
\text { pesquisadas. }\end{array}$ & $\begin{array}{l}\text { Aderente ao estudo anterior, } \\
\text { pois teve achado semelhante, } \\
\text { e, houve evolução quanto à } \\
\text { utilização desta prática. }\end{array}$ \\
\hline $\begin{array}{l}\text { Custeio do } \\
\text { Ciclo de Vida } \\
\text { dos Produtos }\end{array}$ & Não pesquisou. & $\begin{array}{l}\text { Utilizam a ferramenta, no } \\
\text { entanto, mantêm somente o } \\
\text { tradicional controle dos } \\
\text { custos internos e de } \\
\text { produção. }\end{array}$ & $\begin{array}{l}\text { Utilizam e exploram } \\
\text { todos os estágios } \\
\text { desta ferramenta } \\
\text { (interna, produção, } \\
\text { estabilização e } \\
\text { declínio) }\end{array}$ & $\begin{array}{l}\text { Aderente ao estudo anterior, } \\
\text { pois teve achado semelhante, } \\
\text { e, houve evolução quanto à } \\
\text { utilização desta prática. }\end{array}$ \\
\hline $\begin{array}{l}\text { Análise da } \\
\text { Cadeia de Valor }\end{array}$ & Não pesquisou. & $\begin{array}{l}\text { Somente uma parte da } \\
\text { amostra pesquisada utiliza } \\
\text { esta ferramenta. }\end{array}$ & $\begin{array}{l}\text { Todas as empresas } \\
\text { fazem uso desta } \\
\text { prática. }\end{array}$ & $\begin{array}{l}\text { Aderente ao estudo anterior, } \\
\text { pois teve achado semelhante, } \\
\text { e, houve evolução quanto a } \\
\text { utilização desta prática. }\end{array}$ \\
\hline
\end{tabular}

Fonte: Elaborado pelos autores.

Como pode ser observado no Quadro 3, e respondendo ao objetivo da pesquisa, o resultado obtido retrata que as empresas estão dando preferências às práticas contemporâneas em relação aos métodos tradicionais de controle e gestão de custos. A adoção do Custeio e Gestão Baseados em Atividades ( $\mathrm{ABC}$ e $\mathrm{ABM}$ ) é uma exceção, explicado pelo baixo número de empresas (20\%) que utilizam deste método para atribuir custos aos produtos, devido à complexidade de implantação e necessidade de mudanças profundas no sistema.

Quanto à comparação desta pesquisa com os estudos anteriores de Souza, Lisboa e Rocha (2003) e Reckziegel, Souza e Diehl (2007), pode-se concluir que houve uma evolução em relação à adoção destas práticas de gestão de custo, no qual, as empresas enfatizam métodos que possam reduzir os custos para alcançar lucros desejáveis e conquistar maior fatia do mercado.

Algumas considerações finais podem ser deduzidas a partir dos resultados desta pesquisa: a) apesar de amplamente discutidas e divulgadas pela academia, as novas e aperfeiçoadas práticas de gestão de custo como ferramenta para a tomada de decisão ainda não têm, na atualidade, utilização expressiva nas empresas; b) nas empresas não se utilizam as novas e aperfeiçoadas ferramentas de gestão de custo, devido à necessidade de elevados investimentos e consequente baixa relação custo-benefício; c) nas empresas percebe-se uma evolução quanto à utilização das práticas de custos, no qual, houve uma aderência maior dessas práticas em relação ao estudo realizado por Souza, Lisboa e Rocha (2003) e Reckziegel, Souza e Diehl (2007).

Com exceção do custeio e gestão baseado em atividades ( $\mathrm{ABC}$ e $\mathrm{ABM}$ ), as outras práticas são utilizadas pelas empresas e como pode ser visto no Quadro 3, referente a comparação

R. Cont. Ufba, Salvador-Ba, v. 9, n. 3, p. 81 - 103, set-dez 2015 
dos estudos anteriores com a presente pesquisa, houve evolução das demais práticas de gestão de custos. Referente às contribuições do estudo, a pesquisa auxiliou na formação acadêmica e na descoberta de novos conhecimentos no domínio científico e literário, sendo que por este trabalho foi possível ampliar a fronteira do conhecimento e estabelecer novas relações de causalidade para os fatos conhecidos e/ou apresentar novas conquistas para o respectivo campo da ciência.

Ressalta-se que, como limitação do estudo, têm-se a comparação dos resultados com pesquisas anteriores realizadas em contextos econômicos, setores de atividades e regiões distintas das empresas desta pesquisa. No entanto, estes não invalidam a comparação, pois o avanço da aplicabilidade destas ferramentas é observado por meio de pesquisas, de forma a contribuir para a formação de uma teoria universal, que se forma à medida que as ferramentas estudadas se aplicam a todos os segmentos de atuação, contextos econômicos e regiões.

Quanto aos trabalhos acadêmicos direcionados a novos desenvolvimentos, um aspecto relevante que deve ser considerado nos estudos dessa natureza refere-se ao entendimento de que o conhecimento renova-se e jamais será esgotado. Por esse motivo, novas pesquisas relacionadas ao tema devem ser efetuadas para contribuir com o desenvolvimento da ciência da contabilidade de custos bem como suprir lacunas deixadas por este estudo. Com base nos resultados encontrados referente ao tema práticas de gestão de custos, recomenda-se aplicar esse estudo a setores diferentes dos estudados aqui em e outras pesquisas, de modo a identificar se os resultados são semelhantes, contribuindo para o desenvolvimento do ensino e pesquisa em práticas de gestão de custo.

\section{REFERÊNCIAS}

BRIMSON, J. A. Contabilidade por atividades: uma abordagem de custeio baseado em atividades. São Paulo: Atlas, 1996.

CERVO, A. L.; BERVIAN, P. A. Metodologia científica. São Paulo: Makron Books, 1996.

CORONETTI, J., BEUREN, I. M., SOUSA, M. A. B. Os métodos de custeio utilizados nas maiores indústrias de Santa Catarina. Gestão.Org, v. 10, n. 2, p.324-343, maio/ago., 2012.

Eldenburg, L. G., WOlCOTT, S. K. Como Medir, Monitorar e Motivar o Desempenho. Rio de Janeiro: LTC, 2007.

EYERKAUFER, M. L., COSTA, A., FARIA, A. C. Métodos de custeio por absorção e variável na ovinocultura de corte: estudo de caso em uma cabana. Organizações Rurais \& Agroindustriais, Lavras, v. 9, n. 2, p. 202-215, 2007.

FERREIRA, F. B., SCHNORR, C. Práticas de gestão de custos logísticos: um estudo de caso em empresa gaúcha do setor alimentício. Congresso Brasileiro de Custos, XVIII, Anais... Rio de Janeiro, RJ, 2011.

FERNANDES, J. C. C.; SLOMSKI, V. A gestão de custos no contexto da qualidade no serviço público: um estudo entre organizações brasileiras. São Paulo, 2011.

GARRISON, R. H., NOREEN, E. W., Contabilidade Gerencial. 9. ed., São Paulo: Editora LTC, 2001.

GIL, A. C. Como elaborar Projetos de Pesquisa. São Paulo: Atlas, 2002.

R. Cont. Ufba, Salvador-Ba, v. 9, n. 3, p. 81 - 103, set-dez 2015 
HANSEN, D. R., MOWEN, M. M. Gestão de Custos Contabilidade e Controle. São Paulo: Cenguage Learning, 2009.

IUDÍCIBUS, S., MARTINS, E., GELBCKE, E. R., SANTOS, A., Manual de Contabilidade Societária. São Paulo: Atlas, 2010.

LEONE, G. S. G. Curso de contabilidade de custos. São Paulo: Atlas, 1997

LEONE, G. S. G. Custos: planejamento, implantação e controle. São Paulo: Atlas, 2000.

MARTINS, E. Contabilidade de Custos. São Paulo: Atlas, 2010.

PADOVEZE, C. L. Contabilidade gerencial em enfoque em sistema de informação contábil. São Paulo: Atlas, 2009.

PElEiAS, I. R., CESTARE, T. B., MEGlorini, E., AlMEIDA, C. A. L. Proposta de relatórios para gestão de custos em uma indústria calçadista de pequeno porte da cidade de São Paulo. ABCustos Associação Brasileira de Custos, n. 2, p. 103 -121, maio/ago., 2010.

PEREIRA, M. J., ESPEJO, M. M. S. B. Prioridades estratégicas e gestão de custos: a relação conforme a percepção dos gestores nos hotéis de médio e grande porte da Cidade do Salvador BA. Congresso Brasileiro de Custos, XVII, Anais... Belo Horizonte, MG, 2010.

PEREIRA, L. S, VASCONCELOS, P. H.; LUZ, J. R. M. Gestão estratégica de custos: um diferencial competitivo nas micro e pequenas empresas em Campina Grande - PB. Congresso Brasileiro de Custos, XVIII, Anais... Rio de Janeiro, RJ, 2011.

PINHEIRO, G. R., RODRIGUES, M. V., BARRETO, L. R. Custeio Baseado em Atividade na gestão de uma instituição prestadora de serviços educacionais. Congresso Brasileiro de Custos, XVIII. Anais... Rio de Janeiro, RJ, 2011.

PINZAN, A. F. Métodos de custeio e seus propósitos de uso: análise por meio de estudos de casos múltiplos. 136 f. 2013. Dissertação (Mestrado em Ciências Contábeis) Faculdade de Economia, Administração e Contabilidade da Universidade de São Paulo-USP, São Paulo, 2013.

PITELA, A. C., ESPEJO, M. M. S. B., CRUZ, A. P. C., ESPEJO, R. A. Sistemas Contábeis de Apuração e Controle de Custos: Uma Pesquisa de Campo em Empresas Industriais Paranaenses. Congresso Brasileiro de Custos, XV. Anais... Curitiba, PR, 2008.

RECKZIEGEL, V., SOUZA, M. A., DIEHL, C. A. Práticas de Gestão de Custos Adotadas por Empresas Estabelecidas nas Regiões Noroeste e Oeste do Estado do Paraná. Revista Brasileira de Gestão de Negócios, v. 9, n. 23, jan. / abr., p. 14-27, 2007.

ROBLES JUNIOR, A. Custos da qualidade: uma estratégia para competição global. São Paulo: Atlas, 1996.

ROSA, P. M., CAMACHO, R. R., YU, Z. Y. Custeio Alvo em uma empresa de Comunicação Visual: um estudo de caso. Congresso Brasileiro de Custos, XVIII, Anais... Rio de Janeiro, RJ, 2011.

SANTOS, C. M. S., BORNIA, A. C., LEITE, M. S. A. Sistema de Gestão de Custos Associado à Cadeia de Valor. Revista da Associação Brasileira de Custos, v. 1, n. 1, jan. /abr., 2010.

R. Cont. Ufba, Salvador-Ba, v. 9, n. 3, p. 81 - 103, set-dez 2015 
SILVA, U. B., MENDONÇA, K. F. A importância da gestão dos custos para o setor varejista de vestuários: um estudo no município de Teófilo Otoni, MG. Congresso Brasileiro de Custos, XVIII, Anais... Rio de Janeiro, RJ, 2011.

SOUZA, M. A. S., SILVA, É. J., PILZ, N. Práticas de Gestão Estratégica de Custos: Um estudo em uma empresa multinacional brasileira. RCO - Revista de Contabilidade e Organizações, FEA-RP/USP, v. 4, n. 9, p. 145-167, mai./ago., 2010.

SOUZA, M. A., LISBOA, L. P., ROCHA, W. Práticas de Contabilidade Gerencial Adotadas por Subsidiárias Brasileiras de Empresas Multinacionais. Revista Contabilidade \& Finanças - USP, São Paulo, n. 32, p. 40 - 57, maio/ago., 2003. 